\title{
Incidencia del virus del enanismo amarillo de la cebada (BYDV) en cultivos de trigo (Triticum spp) en la región sur del Paraguay
}

\author{
Incidence of barley yellow dwarf virus (BYDV) in wheat (Triticum spp) in the \\ southern region of Paraguay
}

\author{
Luis Roberto González Segnana ${ }^{1}$, Francisco Agustín Vergara Ocampos ${ }^{1}$, Cristhian \\ Grabowski $^{1}$, Rebeca González ${ }^{1}$, Osmar Arias y Silvestre Ayala ${ }^{1}$ \\ ${ }^{1}$ Facultad de Ciencias Agrarias, Universidad Nacional de Asunción (FCA-UNA). San Lorenzo, Paraguay. \\ * Autor para correspondencia (luis.gonzalez@agr.una.py) \\ Recibido: 29/04/2015; Aceptado: 17/06/2015. \\ http://dx.doi.org/10.18004/investig.agrar.2015.junio.60-64
}

\section{RESUMEN}

El virus de enanismo amarillo de la cebada (Barley yellow dwarf virus - BYDV) es un virus ampliamente distribuido en el mundo afectando a diversas Poáceas siendo transmitido por diferentes especies de áfidos. Se realizaron controles por Test de Elisa mediante muestreos durante los periodos agrícolas 2013 y 2014 para determinar los serotipos predominantes en los cultivos de trigo en la región sur del Paraguay que incluyeron los distritos: Fram, Obligado, Bella Vista y Capitán Miranda, igualmente durante el periodo agrícola 2014 se instalaron trampas tipo Moericke a fin de identificar y cuantificar las poblaciones de áfidos presentes durante el desarrollo del cultivo. Los resultados demostraron una amplia distribución del BYDV-PAV en las muestras analizadas; se obtuvo solo un caso positivo para el BYDV-MAV; el CYDV-RPV no fue detectado. Los muestreos realizados de la población de áfidos demostraron que la especie más abundante fue Rhopalosiphum padi L., demostrando su alta eficiencia en la transmisión del serotipo PAV.

Palabras clave: BYDV, CYDV, Virus, Trigo, Áfidos.

\begin{abstract}
Barley yellow dwarf virus (BYDV) is widely distributed in the world, affecting various Poaceae and being transmitted by different species of aphids. Monitoring by ELISA tests on samplings during the 2013 and 2014 agricultural year were carried out to determine the predominant serotypes in wheat crops in the southern region of Paraguay, in the districts of Fram, Obligado, Bella Vista and Capitan Miranda. During the agricultural period 2014 Moericke type traps were set up to identify and quantify aphid populations present during crop development. The results showed a wide distribution of BYDV-PAV strain in the samples analyzed but only one positive case for BYDV-MAV strain and no CYDV-RPV strain was detected. The aphid population samplings showed that the most abundant species was Rhopalosiphum padi L., proving its high efficiency in the transmission of PAV serotype.
\end{abstract}

Key words: BYDV, Virus, Wheat, Aphids.

\section{INTRODUCCIÓN}

El virus de enanismo amarillo de la cebada (Barley yellow $d$ warf virus - BYDV) es una de las enfermedades virales más importante de los cereales en el mundo (Lapierre y Signoret 2004), pudiendo causar pérdidas económicas considerables en diversos cereales como trigo, cebada, arroz, avena y centeno (Plumb 2002). Pertenece a la familia Luteoviridae y está compuesto por partículas isométricas

de 25 a $30 \mathrm{~nm}$ con su genoma viral de RNA monocatenario de sentido positivo (Miller y Rosochova 1997).

Este patógeno, puede ser transmitido por varias especies de áfidos (Hemíptera, Aphididae) de manera circulativa 
no propagativa sin transmisión transovarial; no se transmite mecánicamente, ni por semilla (Gray y Gildow 2003). Se clasifican en dos géneros: el género Luteovirus que incluyen las especies Barley yellow dwarf virus (BYDV): BYDV-PAV, BYDV-MAV y el BYDV-PAS; y el género Poleurovirus que contiene la especie Cereal yellow dwarf virus (CYDV): CYDV-RPV y el CYDVRPS (D’ Arcy y Domier, 2005).

Rochow (1969) describe cinco distintos tipos (serotipos) de BYDVs basados en la habilidad de las especies de áfidos de adquirir y transmitir cada virus. En la misma, cada virus fue identificado con la primera letra del nombre científico de la especie de áfido más eficiente: BYDV-MAV transmitido por Sitobium avenae Fabr., BYDV-RPV transmitido por Rhopalosiphum padi L., BYDV-RMV transmitido por Rhopalosiphum maidis Fitch, BYDV-SGV transmitido por Schizaphis graminum Rond. y BYDV-PAV transmitido por Rhopalosiphum padi L. y por Sitobium avenae Fabr.

El cultivo del trigo en el Paraguay tiene actualmente una gran expansión, donde pasó de importador, a exportador del cereal con una producción total de 1.314.046 t y rendimientos de $2080 \mathrm{Kg} \mathrm{ha}^{-1}$ según estadísticas de la Cámara Paraguaya de Exportadores y Comercializadores de Cereales y Oleaginosas (CAPECO 2014). Una de las limitaciones del cultivo son las enfermedades, entre las que se citan las de etiología viral.

Resulta de gran importancia identificar las enfermedades virales y sus serotipos predominantes, así como la identificación y cuantificación de las especies de áfidos en la principal región productora de trigo del Paraguay. El objetivo de la presente investigación fue identificar los serotipos del BYDV y los áfidos vectores presentes en el cultivo de trigo en la región sur del Paraguay.

\section{MATERIALES Y MÉTODOS}

El periodo de investigación abarcó los ciclos del cultivo de los años 2013 y 2014 durante los meses de junio a setiembre de cada año. Se efectuaron viajes periódicos a la principal zona triguera del sur de Paraguay, incluyendo los distritos: Fram, Obligado, Bella Vista y Capitán Miranda, donde se encuentra el Centro de Investigaciones Capitán Miranda (CICM) dependiente del Instituto Paraguayo de Tecnología Agraria (IPTA), que cuenta con uno de los bancos de germoplasma de mayor diversidad de trigo del país.
Asimismo, se realizaron colectas dirigidas en sitios donde por referencia de los técnicos de la zona fueron identificados síntomas sospechosos o similares a los ocasionados por virus (mosaico o deformación foliar, clorosis, enanismo, coloración púrpura). Igualmente, fueron recibidas muestras sospechosas remitidas por productores interesados, extensionistas y asesores técnicos colaboradores de las zonas de producción. El total de muestras analizadas fue de 295, durante los dos períodos de evaluación.

Las muestras fueron trasladadas en bolsas de papel debidamente identificadas y numeradas para su análisis al Laboratorio del Departamento de Biología de la Facultad de Ciencias Agrarias (FCA), Universidad Nacional de Asunción (UNA) en la ciudad de San Lorenzo. Todas las muestras fueron procesadas para la determinación del o los tipo/s de virus presente/s. Para ello se empleó la técnica serológica de DAS-ELISA (Double Antibody Sandwich - Enzyme Linked Immunosorbant Assay).

El material recibido fue procesado de forma homogénea para determinar cuál de los tres virus estaba presente en la zona estudiada. Para cada test de detección viral, además de los anticuerpos específicos, se incluyó a sus respectivos controles positivos y negativos. Tanto el procesamiento previo de las muestras vegetales, como la preparación de los kits de detección, fueron llevados a cabo de acuerdo a las instrucciones del fabricante (AGDIA®). Se emplearon dos anticuerpos para detectar los serotipos del BYDV-PAV, BYDV-MAV y uno para el CYDV-RPV por su disponibilidad en el mercado.

Las soluciones tampones de lavado y de extracción fueron preparadas siguiendo los protocolos establecidos para cada test (AGDIA®). Posterior a los períodos de incubación se procedió a la lectura de las microplacas a través de un equipo lector colorimétrico de la marca "Perlong" (modelo DNM 9602). Dicho equipo actúa como un espectrofotómetro midiendo la intensidad del color en cada pocillo de la placa a una absorbancia de 405 $\mathrm{nm}$ de luz visible.

Los datos de cada test fueron impresos desde el equipo lector serológico y los datos se analizaron posteriormente mediante un cálculo manual. Fueron consideradas positivas las lecturas que superaron por más del doble al valor obtenido en los controles negativos, luego de un tiempo de incubación final de dos horas; salvo para el caso específico del CYDV-RPV, en el cual se empleó inclusive las lecturas de hasta tres horas, de acuerdo a las 
recomendaciones del fabricante (AGDIA®). Posterior a la fase de procesamiento, las muestras vegetales positivas para cada virus fueron seccionadas y almacenadas con granos de Cloruro de calcio $\left(\mathrm{CaCl}_{2}\right)$ bajo refrigeración para estudios posteriores de caracterización.

La colecta e identificación de los áfidos se realizó en forma semanal durante los meses de julio a agosto del año 2014. El método de muestreo utilizado fue con trampas, tipo Moericke que consiste en un recipiente de metal con interior color amarillo con dimensiones $30 \mathrm{~cm} \mathrm{x} 45 \mathrm{~cm} \mathrm{y}$ $5 \mathrm{~cm}$ de altura que estaban colocadas sobre el suelo, en las márgenes y dentro de los cultivos en lugares bien visibles. Las mismas contenían agua con $0,5 \%$ de formaldehído $\mathrm{CH}_{2} \mathrm{O}$, con $\mathrm{PM}$ de 30,03 y $0,2 \%$ de detergente líquido incoloro.

Al momento de la colecta de insectos, el líquido del recipiente fue filtrado con un colador, recuperando los insectos y siendo colocados en frascos de plástico con alcohol al $70 \%$ para su conservación y traslado al laboratorio de biología, para su posterior identificación (Belda et al. 1994). La identificación de áfidos se realizó mediante claves taxonómicas elaboradas por Valle da Silva y Salvadori (2005).

\section{RESULTADOS Y DISCUSIÓN}

Las pruebas serológicas, practicadas a las muestras colectadas en el año 2013, resultaron positivas para el serotipo BYDV-PAV y negativos para los serotipos BYDV-MAV y CYDV-RPV (Tabla 1).

De las muestras positivas, la mayoría resultaron estar infectadas con BYDV-PAV lo que demuestra la amplia distribución del serotipo PAV en la región sur del Paraguay. Estas muestras corresponden a las variedades comerciales Canindé 11, Itapuá 75 e Itapuá 65 y las líneas experimentales (F6, F7 y EV) evaluadas en el CICM (IPTA). Asimismo, las pruebas serológicas, practicadas a las muestras colectadas en el año 2014, resultaron positivas para los serotipos BYDV-PAV y BYDV-MAV (Tabla 2).

Webby et al. (1993), analizando muestras obtenidas en el año 1988 del CICM, encontraron que el serotipo de BYDV más común fue MAV, por sobre el PAV. Cabe señalar que en el Brasil en las décadas del 70 y 80 hubo un predominio del serotipo MAV, como consecuencia directa de que el áfido dominante era en ese entonces el Metopolophium dirhorum Walk, más eficiente en la transmisión del serotipo MAV (Caetano 1972; Gildow y Rochow 1983), posiblemente la misma situación se presentó en Paraguay en esas décadas.

Tabla 1. Test de ELISA positivos para BYDV-PAV (valor de Absorbancia $405 \mathrm{~nm}$ ) en muestras de trigo colectadas en el periodo 2013. FCA-UNA, San Lorenzo, Paraguay, 2013.

\begin{tabular}{|c|c|c|c|c|}
\hline $\begin{array}{l}\text { Fecha de } \\
\text { colecta }\end{array}$ & $\begin{array}{l}\text { Denominación } \\
\text { del material }\end{array}$ & $\begin{array}{l}\text { Lugar de } \\
\text { colecta }\end{array}$ & $\begin{array}{l}\text { Lectura de } \\
\text { muestra }\end{array}$ & $\begin{array}{l}\text { Control } \\
\text { negativo }\end{array}$ \\
\hline 25/07/2013 & Canindé 11 & CICM & 1,704 & 0,08 \\
\hline 25/07/2013 & Itapua 65 & Col.La Paz & 0,962 & 0,07 \\
\hline 25/07/2013 & F6 87 & CICM & 1,754 & 0,08 \\
\hline $9 / 08 / 2013$ & Itapua 75 & $\begin{array}{c}\text { Cap. } \\
\text { Miranda }\end{array}$ & 1.704 & 0.08 \\
\hline 21/08/2013 & F6 106 & CICM & 1,696 & 0,07 \\
\hline 21/08/2013 & EV 30 & CICM & 1,044 & 0,09 \\
\hline 21/08/2013 & F6 92 & CICM & 0,864 & 0,08 \\
\hline 21/08/2013 & F6 105 & CICM & 0,571 & 0,06 \\
\hline 21/08/2013 & F7 92 & CICM & 0.813 & 0,06 \\
\hline 21/08/2013 & F7 87 & CICM & 0.692 & 0,07 \\
\hline 21/08/2013 & F7 83 & CICM & 0.847 & 0,07 \\
\hline
\end{tabular}

Tabla 2. Test de ELISA positivos para BYDV-PAV y BYDV-MAV (valor de Absorbancia $405 \mathrm{~nm}$ ) en muestras de trigo colectadas en el periodo 2014. FCA-UNA, San Lorenzo, Paraguay, 2014.

\begin{tabular}{lllll}
\hline $\begin{array}{c}\text { Fecha de } \\
\text { colecta }\end{array}$ & $\begin{array}{c}\text { Denominación } \\
\text { del material }\end{array}$ & $\begin{array}{c}\text { Lugar de } \\
\text { colecta }\end{array}$ & $\begin{array}{c}\text { Lectura de } \\
\text { muestra }\end{array}$ & $\begin{array}{c}\text { Control } \\
\text { negativo }\end{array}$ \\
\hline Serotipo BYDV-PAV & & & \\
\hline $08 / 09 / 2014$ & F5 SEG & CRIA & 0,456 & 0,09 \\
$08 / 09 / 2014$ & BC 68 & CRIA & 0,709 & 0,09 \\
$08 / 09 / 2014$ & REG 17 & CRIA & 0,305 & 0,09 \\
$25 / 08 / 2014$ & REG X & CRIA & 0,868 & 0,13 \\
$04 / 08 / 2014$ & Canindé 11 & CRIA & 1,172 & 0,11 \\
\hline Serotipo BYDV-MAV & & & \\
\hline $05 / 08 / 2014$ & Codetec 150 & Bella & 0,288 & 0,07 \\
\hline & & Vista Sur & & \\
\hline
\end{tabular}


Por otro lado, para la especie MAV del BYDV se obtuvo un único test positivo para una muestra colectada en la localidad de Bella Vista Sur, Itapúa; en el mes de Agosto. Dicha muestra corresponde a la variedad comercial Codetec 150. En cuanto que para el CYDV- RPV, no se obtuvieron resultados positivos en ninguna de las muestras analizadas.

Los muestreos realizados de la población de áfidos durante el periodo de cultivo 2014 en la región Capitán Miranda (CICM) muestran a la especie Rhopalosiphum padi L. como la más abundante (Tabla 3 ).

Tabla 3. Fechas de colecta y cantidad de áfidos colectados en la localidad de Capitán Miranda, Departamento de Itapúa en el año 2014. FCA - UNA, San Lorenzo, Paraguay, 2014.

\begin{tabular}{ccccc}
\hline \multicolumn{5}{c}{ Especies } \\
Fecha de & $\begin{array}{c}\text { Rhopalosiphum } \\
\text { padi L. }\end{array}$ & $\begin{array}{c}\text { Rhopalosipum } \\
\text { maidys Fitch }\end{array}$ & $\begin{array}{c}\text { Sitobion } \\
\text { avenae } \\
\text { Fabr }\end{array}$ & Total \\
\hline $18 / 06 / 2014$ & 253 & 8 & 1 & 262 \\
$25 / 06 / 2014$ & 27 & 0 & 0 & 27 \\
$14 / 07 / 2014$ & 77 & 1 & 2 & 80 \\
$31 / 07 / 2014$ & 1 & 0 & 0 & 1 \\
$04 / 08 / 2014$ & 3 & 0 & 0 & 3 \\
$14 / 08 / 2014$ & 6 & 1 & 0 & 7 \\
$22 / 08 / 2014$ & 9 & 0 & 1 & 10 \\
$25 / 08 / 2014$ & 1 & 1 & 0 & 2 \\
\hline Totales & 377 & 11 & 4 & 392 \\
\hline$\%$ & 96,17 & 2,8 & 1,02 & 100 \\
\hline
\end{tabular}

La predominancia del BYDV-PAV así como de $R$. padi L. se registra en varias zonas productoras de trigo como en el Brasil (Schons y Dalbosco, 1999; Lanzarini et al. 2007; Parizoto et al., 2013), en la Argentina (Alemandri y Truol 2009) y en otras regiones (Fabre et al., 2005; Burrows et al. 2009; Yu, 2013), donde R. padi L es el vector más importante del BYDV-PAV debido a su abundancia durante el ciclo del cultivo y su eficiencia en la transmisión del serotipo BYDV-PAV.

La población de áfidos está considerada como el factor epidemiológico más importante en la incidencia del BYDV en el cultivo de trigo (Fabre et al. 2005), por lo tanto resulta de gran interés práctico conocer la población de áfidos durante el desarrollo del cultivo, y en particular al Rhopalosiphum padi L., de modo a establecer los métodos de control más apropiados y evitar grandes pérdidas ocasionadas por el complejo de BYDV-PAV.

\section{CONCLUSIÓN}

Los Test serológicos llevados a cabo por ELISA demuestran la predominancia del virus del enanismo amarillo de la cebada (BYDV) serotipo PAV en la región triguera del sur del Paraguay, en correspondencia con la también abundancia del vector más eficiente para el mismo el Rhopalosiphum padi L. El Cereal yellow dwarf virus (CYDV-RPV) no fue detectado en el presente estudio.

\section{AGRADECIMIENTOS}

Al Instituto de Biotecnología Agrícola (INBIO) por la financiación del Proyecto. A todo el personal Técnico del Programa de Trigo del Centro de Investigación Agrícola de Capitán Miranda (IPTA) por el soporte en las actividades de campo.

\section{REFERENCIAS BIBLIOGRÁFICAS}

Alemandri, VM; Truol, GAM. 2009. Barley yellow dwarf virus (BYDV-PAV) y sus variantes. En G.A.M. Truol (Ed.), Enfermedades virales asociadas al cultivo de trigo en Argentina: reconocimiento, importancia, formas de transmisión y manejo (pp. 15-20). Córdoba: INTA Ediciones.

Belda, J; Aguirre, A; Mirasol, E; Cabello, T. 1994. Dinámica de población de pulgones alados (Horn.; Aphididae) en cultivos del levante de Almería (en línea). Bol San Veg Plagas 20: 329-337. Consultado 8 de set 2013. Disponible en www.researchgate.net /...pulgones.../72e7e52260a8a5e990.pdf

Burrows, M; Franc, G; Rush, C; Blunt, T; Ito, D; Kinzer, K; Olson, J; O’Mara, J; Price, J; Tande, C; Ziems, A; Stack, J. 2009. Occurrence of Viruses in Wheat in the Great Plains Region, 2008. Plant Health Progress no. July 2009: 1-7.

Caetano, VR. 1972. Estudo sobre o virus do nanismo amarelo da cevada em trigo no Rio Grande do Sul. DS Thesis, ESALQ-USP. Piracicaba SP.

CAPECO (Cámara Paraguaya de Exportadores y Comercializadores de Cereales y Oleaginosos PY). 
2014. Área de siembra, producción y rendimiento. (en línea) Consultado 17 jun 2015. Disponible en http://www.tera.com.py/capeco/index.php?id=trigo

D’Arcy CJ; Domier LL. 2005. Family luteoviridae. In: Fauquet CM; Mayo MA; Maniloff J; Desselberger U; Ball LA. (Eds) Virus Taxonomy. VIIIth Report of International Committee on Taxonomy of Viruses. London UK. Elsevier Academic Press. Pp. 891-900.

Fabre, F; Plantegenest, M; Mieuzet, L; Dedryver, CA; leterrier, JL; Jacquot, E. 2005. Effects of climate and land use on the occurrence of viruliferous aphids and the epidemiology of barley yellow dwarf disease. Agriculture, Ecosystems and Environment 106: 49-55.

Gray, S; Gildow, FE. 2003. Luteovirus-Aphid Interactions. Annual Review of Phytopathology. 41: 539-566.

Gildow, FE; Rochow, WF. 1983. Barley yellow dwarf in California. Vector competence and luteovirus identification. Plant Dis 67: 140-143.

Lanzarini, AC; Schons, J; Salvadori, JR; Nienow, AA; Nicolini-Teixeira, F; Binotto-Missiura, F; Deuner, E. 2007. Avaliação de danos causados pelo Barley yellow dwarf virus: PAV em cultivares de trigo no Brasil. Fitopatologia Brasileira 32(6): 512-517.

Lapierre, H; Signoret, PA. 2004. Viruses and Virus Diseases of Poaceae (Gramineae). France, INRA Editions, 857 p., (Sciences de la vie).

Miller, WA; Rosochová, L. 1997. Barley yellow dwarf viruses. Annual Review of Phytopathology 35:167-190.
Rochow, WF. 1969. Biological properties of four isolates of Barley yellow dwarf virus. Phytopathology 59: 1580-1589.

Parizoto, G; Rebonatto, A; Schons, J; Lau, D. 2013. Barley yellow Dwarf vírus-PAV in Brasil: Seasonal Fluctuation and biological characteristics. Tropical Plant Pathology 38(1): 11-19.

Plumb, RT. 2002. Viruses of Poaceae: a case history in plant pathology. Plant Pathology 51: 673-682.

Schons, J; Dalbosco, M. 1999. Identific0acao de estirpes do virus do nanismo amarelo da cevada. Fitopatologia Brasileira 24: 359.

Valle da Silva, PR; Salvadori, JR. 2005. Identificacao dos principais parasitoides (Himenóptera: Aphelinidae y Braconidae, Aphidiinae) envueltos no controles biológico de pulgoes (Hemíptera: Aphididae) em trigo no sul do Brasil. Passo Fundo BR. Embrapa Trigo. Comunicado técnico, 22. 7 p.

Webby, GN; Lister, RM; Burnett, PA. 1993. The occurrence of barley yellow dwarf viruses in CIMMYT bread wheat nurseries and associated cereal crops during 1988-1990. Annals of Applied Biology 123(1): 63-74.

Yu, W. 2013. Virus transmission efficiency: investigation on Chinese clone diversity of wheat aphids and role of aphid endosymbionts. PhD dissertation. Gembloux, Belgium, University of Liege, Gembloux Agro-Bio Tech. 